\title{
Minimalism in SLA
}

\author{
Parviz Maftoon \\ College of Foreign Languages and Literature, Science and Research Branch, IAU, Tehran, Iran \\ Nima Shakouri \\ Roudbar Branch, Islamic Azad University, Rasht, Iran
}

\begin{abstract}
What Chomsky and his followers persist is that thought is not influenced by language and is only expressed by it. Zahedi (2008) claims Chomsky's determinist approach to language comprises three distinct problems: Humboldt's Problem - what constitutes knowledge of language-Plato's Problem-how such knowledge is acquired — and Descartes' Problem — how such knowledge is put to use, all of which are the main concern of first language acquisition but not second language learning. The present paper is an attempt to elucidate the concept of minimalism and presents an answer to whether the penetration of minimalism into the realm of SLA is plausible. In fact, assuming language as a specific faculty that imposes the output in first language acquisition is not on a par to claim that second language learners acquire the language in much the same way as their first language.
\end{abstract}

Index Terms - minimalism, maximalism, legibility condition, UG

\section{INTRODUCTION}

An interesting point about human beings is that they are keen on learning about recent discoveries; however, they know nothing about the earlier discoveries. In fact, they show little interest in what have been discovered. Nevertheless, it is a truism that understanding of the past provides an explanatory tool (Boeckx, 2006). Accordingly, what behaviorists have achieved in the past paved the way and provided an empirical tool for Chomsky (1957) to claim that relying on external input cannot account for the creative aspect of language use. In other words, what makes Chomsky assert that a native speaker is able to create and understand infinite number of sentences never heard before was a tool provided by behaviorists. In fact, Chomsky's rejection of any behaviorist account helped him shape what came to be known as the cognitive revolution - a child is born with a language acquisition device (LAD) playing a central role in the acquisition and use of behavior. From this time, the central question in the realm of linguistics was a problem argued by Chomsky: how to account for children's acquisition of their native language. Along the same line, the knowledge of language (competence) is tacit rather than explicit; thus it is no good asking a native speaker a question such as "how do you form negative sentences?" (Radford, 1997, p. 2). As Radford adds:

Perhaps the richest vein of readily available evidence which we have about the nature of grammatical competence lies in native speakers' intuitions about the grammaticality and interpretations of words, phrases and sentences in their native language. For example, preschool children often produce past-tense forms like goed, comed, seed, buyed, etc. and any adult native speaker of (modern Standard) English will intuitively know that such forms are ungrammatical in English, and will know that their grammatical counterparts are went, came, saw and bought. (p. 3)

To make the task of linguistics more precise, Chomsky (1957) claims that there are three stages in which adequacy can be attained in grammar. In other words, grammar is a theory of language that must achieve three levels of adequacy:

1. Observational adequacy. The lowest level of adequacy is achieved if a grammar presents the observed primary linguistic data correctly. In other words, a grammar can accept or reject a sentence. That is, the grammar is able to distinguish those strings of words which are sentences of the language from those which are not sentences of the language.

2. Descriptive adequacy: A grammar is descriptively adequate if it correctly accounts for the native speakers' intuition; whether a sentence is grammatical or not takes place in the realm of descriptive adequacy. The main concern here is to know what an ideal speaker knows. For example, in the sentence Sara eats an apple, a native speaker knows that an apple is understood as the object in the above sentence.

3. Explanatory adequacy. This stage of adequacy determines how a child acquires a first language. The central question of linguists, as Bourke (2005) outlines, is as follows: How does the child go from primary linguistic data, i.e., well-formed, short sentences in the target language, to a grammar for that language, i.e., a procedure for generating a potentially infinite number of sentences?

Through a critical lens, one can ask what Chomsky and his followers have to offer for second language acquisition (SLA). What is implausible is that the concept of the faculty of language is used in relation with first language acquisition, but not SLA. If we want to generalize Chomsky's proposal for the first language acquisition to SLA, it seems to be a futile attempt. Besides, recently, several scholars (e.g., Cook, 1997; Schwartz, 1997) are not compatible with comparing L2 learners to native speakers of the L2 based on the properties of UG. In other words, the use of ideas 
and techniques employed in L1 does not always transfer to L2 acquisition for various reasons and employing them in L2 may hinder the process of language acquisition.

\section{LITERATURE REVIEW}

\section{A. The Minimalist Program (MP) and SLA}

Working in SLA within the framework of minimalism is a "challenge" (Balcon, 2001, p. 306) since researchers need to keep up with changes in syntactic theory, as well as changes in SLA. Accordingly, Bley-Vroman's (1983) comparative fallacy warns that "work on the linguistic description of languages can be serially hindered or sidetracked by a concern with the target language" (p. 2). He goes on to hold that "the learner's system is worthy of study of its own right, not just as a degenerate form of the target system" (p. 4). In this regard, Bley-Vroman claims that SLA primarily differs in part from first language (L1) acquisition on the basis of differences in their outcomes. That is, the property of the grammar of L2 learners is different from that of native speakers (White, 1998).

Drawing on the concepts of minimalism to account for the process of SLA is not an easy task. Nevertheless, the cautionary note by Chomsky (1995, cited in Balcon, 2001) makes us alert that one should bear in mind that MP is a program, not a theory, even less than the principle and parameters approach, although minimalism emanates from the achievement of the principles and parameters program (Boecks, 2006).

MP appeals to the idea that the language faculty of humans shows signs of an optimal design, which seems to suggest that the inner workings conform to a very simple computational law. In other words, MP considers a linguistic expression as the optimal realization of the interface conditions, where optimality is determined by the economy of UG. Along the same line, MP aims at developing the ideas of economy of derivation and economy of representation (David, 2003). The former, according to David, is a principle stating that movements only occur in order to match interpretable features with uninterpretable features. An example of an interpretable feature is the plural inflection on regular English nouns, e.g. boys. The word boys can only be used to refer to several boys, not a single boy, and so this inflection contributes to meaning, making it interpretable. Besides, English verbs are inflected according to the number of subjects (e.g., Boys run vs A boy runs); however, this information is only interpretable once a relationship is formed between the subject and the verb. Economy of representation, on the other hand, insists the principle that grammatical structures should exist for a purpose; i.e., the structure of a sentence, as David asserts, should be no larger or more complex than required to satisfy constraints on grammaticality. What is plausible is that this faculty is innate; thus, how can this innate faculty be imagined in SLA? Moreover, if the knowledge of language is predetermined, how can we expect that MP contributes to learning in L2; still, what Chomsky has discussed for decades seems not to be applicable to SLA.

\section{B. Minimalism and Poverty of Stimulus}

What is clear is that linguistic evidence available to a child is too impoverished to account for how the child comes from small sample of cases s/he gets as input to a grammar that lets him/her generate an infinite number set of wellformed sentences of the language. Along the same line, the basic tenet of argument, to Longa and Lorenzo (2008) is that "the amplitude and rich articulation of the knowledge about language of any normal child strongly contrasts with the scarcity and degeneracy of the data she comes across" (p. 542). Actually, the deficiencies of the data are of different kinds, which Thomas (2002, cited in Longa \& Lorenzo, 2008) classifies into three main groups:

- Degeneracy. Stimuli are poor because they contain defects such as false starts, interrupted fragments, lapses, etc.

- Finiteness. Stimuli are poor because they represent a very limited, idiosyncratic, and accidental array of data from an infinite set of possibilities.

- Partiality. Stimuli are poor because certain phenomena that the child has no problems dealing with are completely absent from the array of data at her disposal. (p. 543)

The concept of poverty of stimulus can be clarified through an example. Imagine a child makes the sentence Sara is happy when she is here into the question form Is Sara happy when she is here? Now a legitimate question to ask is how the child knows to move is from the main clause and not from the embedded clause? There are two possible answers to this question. Either the child is exposed to many such clauses, or the child is built so as to consider viable only such sentence formation rules. If we choose the first answer, we are implicitly driven to this notion that rules are learned on the basis of available data. However, if we accept this proposal for L1, we can simply deny it in SLA; children only learn the rules that they are exposed to. In this regard, we can claim the creation of such sentences will be finite. Then, we should expect if the child is not exposed to particular data, s/he will not be able to produce correct sentences. This is an example of what linguists refer to as the poverty of stimulus argument: the linguistic input (stimulus) given to the child is not rich enough to account for what s/he tacitly knows. This argument must not raise such issues that poverty of stimulus is a pro-innateness argument. MP is not an attempt to question the concept of innateness (Longa \& Lorenzo, 2008). Accordingly, Longa and Lorenzo contend:

Any effort to explain language acquisition as a process guided from stimuli and the external circumstances of the child must be abandoned if it proves to be correct. If, on the contrary, stimuli are proved to be rich and capable of serving as the model from which to derive any sort of grammatical rule or principle, then an empiricist interpretation of language learning is in principle possible. (p. 544) 
To give up the discussion any further, it can be concluded that the poverty of stimulus, according to Longa and Lorenzo, has only an indirect or secondary role in the defenses of innateness. The authors further state that the main purpose of the poverty of stimulus argument is to discredit empiricism. They, nevertheless, maintain the idea of poverty of stimulus argument within the depot of MP is not a pivotal one. It is not among the concern of MP that stimuli given to children are or are not poor. The primary goal of the program, according to the evolutionary psychology, is to discover those systems that account for the implementation of linguistic systems.

However, one of the central questions in the realm of MP is that what kind of knowledge is innate. In embracing the concept of innateness, Longa and Lorenzo claim, there should be a shift from input-output model to a dispositional model (Longa \& Lorenzo, 2008). On elaborating the distinction between input-output model and dispositional model, Longa and Lorenzo assert that the former model, relying on the poverty of stimulus argument, asserts that "the mismatch between, on the one hand, the scarcity and the imperfection of the [input] around children, and, on the other, the sophistication of the system of knowledge finally attained" (p. 547) lends support to a claim that the amount of information encapsulated in the system of knowledge is not derivable from experience. Longa and Lorenzo go on to hold that "the second model, [the] dispositional model, is based on the idea that an innate feature of a species is simply a property determined to appear at a certain point of the developmental process" (p. 547). In effect, dispositional model "treats innate features phenotypical [; that is,] what is innate is the property and not the basis of development" (Longa \& Lorenzo, 2008, p. 547). In the same line, Longa and Lorenzo imply that "a certain property of grammars can be considered innate in spite of not being the answer to a specific grammatical instruction from an innate base" (p. 547). The phenotypical nature of innateness has two implications: (1) it is a feature inherited from the external systems and has its foundations on the compositionality of thought for some and for others as the planitification and execution of motor gestures; and (2) it is a feature somehow unavoidable for any combinational system as held by Chomsky (Longa \& Lorenzo, 2008).

\section{Maximalism versus Minimalism}

From the point of view of the architecture of mind, language faculty plays the role of a bridge by which representations of the external systems become accessible to one another. In support of this, linguists might endorse either maximalist or minimalist perspectives. Whereas Chomsky (1957) is a minimalist, or "lumper," Halliday (1973) is a maximalist, or "splitter" (Bourke, 2005, p. 92). For minimalists, according to Longa and Lorenzo (2008), thought is directly externalizable, and the mind does not need to incorporate a specific grammatical system. This implies that the mechanisms of the faculty of language are not different from the external systems. Maximalists, in contrast, taking the dominant position among the acquisition theories hold that language is a specific faculty that imposes the output. Imagining that second language learners acquire the language in much the same way as they do in learning their first languages does not seem to be plausible. In contrast, Bourke (2005) confers that the basic claim of Hallidayan systemic functional grammar is that every use of English determines the form of the language that is used for that particular purpose. To maximalists, language is a specific faculty that imposes the representational format (grammar) on thoughts in order to be translatable into psychomotor instructions (Zwart, 1998). As Bourke (2005) maintains "grammar is thus a tool for making meaning" (p. 92). An example from the maximalist perspective will clarify the issue. In expressing uncertainty, according to Bourke, one may select various exponents in order to fulfill the same purpose:

Sara may come.

I am not sure whether Sara comes.

Sara is likely to come.

In Halliday's (1973) functional systemic grammar, all meaning comes out of three metafunctions: (1) ideational, (2) interpersonal, and textual. As put by Bourke (2005,) ideational metafunction refers to the use of language in order to represent the world and how we experience it, e.g., to talk about the weather or to say what is going on. Interpersonal metafunction refers to language as an exchange between people, as in greetings, polite requests, etc.; and textual metafunction refers to the ways language holds together as a text, i.e., how it forms a coherent message rather than just a collection of sentences. Accordingly, Halliday (1994, cited in Bourke, p. 93) goes on to hold that the context in which the language occurs is also divided into three parts, the field, the tenor, and the mode:

- The field is basically what is being talked about and relates to the ideational metafunction;

- The tenor has to do with the role relations between the people in the exchange and relates to the interpersonal metafunction; and

- The mode has to do with the nature of the exchange-whether it is spoken or written, and the genre. It is related to the textual metafunction.

Halliday's system, in contrast with Chomsky's, is dynamic and interactive (Maftoon \& Shakouri, 2012). Linearity is absent in Halliday's perspective. Although Hallidayan systemic functional grammar may seem complex and messy (Bourke, 2005), the dynamic nature of language, as to Maftoon and Shakouri (2012), is more compatible with Halliday's (1973) perspective of language. In fact, Bourke (2005) maintains language is processed through a network of systems. At each point in the processing, as Bourke continues "certain options are made and one enters into ever more delicate system networks until eventually the original metafunctional meaning is transmuted into wording" (p. 93). 
Thornton and Wexler (1999) declare that a basic tenet of UG is that much linguistic knowledge is part of the genetic makeup of the child. This knowledge is encoded in the form of universal principles. These principles are only useful to a certain type of mental computations. In fact, the principles of UG prohibit the arrangement of words, certain operations, etc. The MP tries to explain the principles that universally constrain the form of languages. The constraints have assumed to have a central position in theory of UG that endow the child with innate knowledge of syntactic properties. To MP, as Longa and Lorenzo (2008) put forth, it is the faculty of language that is required to adjust to the formal properties of the systems it serves as a cognitive bridge. They also go on to hold that "while [,] according to the maximalist view [,] it is the mind which must be adapted to its linguistic tool, according to the minimalist position[,] it is language which accommodates and develops properties akin to those of other components of mind" (p. 552).

To maximalists, human language is modular from two different perspectives: On the one hand, the faculty of language, as Longa and Lorenzo (2008) declares, "is seen as one of the components (modules) in which the mind is articulated, each one being a specialized system from an anatomical and a functional point of view (external modularity)" (p. 552); on the other hand, the faculty of language is considered internal different subsystems. From the external modularity point of view, language is located at the same level of the analysis of mind as such other components as vision, motor control, while to internal modularists, language is attributed a highly specific set of subsystems, such as case theory and phrase structure theory (Longa \& Lorenzo, 2008). This implies the fact that language is a complex dynamic system; understanding a sentence involves interactions of various components and modules.

\section{Minimalism and Legibility Conditions}

MP postulates that the faculty of language is designed to satisfy legibility conditions, but it may not (Zahedi, 2008, p. 40). There are no output conditions within the faculty of language. The only output conditions are those of bare output conditions external to the faculty of language and imposed by performance systems known as legibility conditions. However, performance systems are also equipped with intellibility conditions which do not impose on the faculty of language. But what motivates the faculty of language to allow generation of illegible expressions, as Zahedi argues, is unknown. Accordingly, the most fundamental hypothesis of MP is that language is an optimal solution to legibility condition which is, according to Zahedi, imposed by the performance systems, external to language but internal to mind. Along the same line, Longa and Lorenzo (2008) declare:

The ultimate foundations of the FL [faculty of language] are certainly not linguistic, the interaction of the external systems during development being responsible for the emergence of a linguistic capacity and with genes perhaps only in charge of the development of those nonlinguistic systems. The growing of the FL is thus to be considered a side effect of the development of the external systems, which establish the conditions that, given a minimum amount of external stimuli, impel the implementation of a linguistic capacity as an aspect of the cognitive equipment of any individual. The FL is therefore an unavoidable result of certain initial nonlinguistic conditions and not the final outcome of an initial state of linguistic knowledge. (p. 548)

Bare output condition implies that in MP there are no output conditions except those imposed externally (i.e., the performance system). They are called output conditions because they operate on interface levels; they are designated as bare since they are no longer part of the computational systems as postulated in Government-Binding, such as filters and ranked constraints (Zahedi, 2008, p. 41). In brief, minimalism takes its point of departure as to what the faculty of language may contain. In this regard, it suffices to say that the Principles and Parameters approach provides language learners with a fixed set of principles common in all languages, and one or more parameters of variations. As Boeckx (2006) mentions, the principles come as a menu. In much the same way, Baker (2001) has likened principles to the list of atoms in the periodic table that may be combined in various ways (the parameters) to form molecules.

\section{E. Minimalism and Computational System}

MP, as a departure from Chomsky's (1957) earliest models, has an inclination towards the dynamic nature of language (Maftoon \& Shakouri, 2012). In this regard, Zwart (1998) states that "the Minimalist Program [MP] deals with the perennial question of how to link sound and meaning" (p. 215). Accordingly, in his earlier work, Chomsky (1957) proposes that the faculty of language, independent of the other faculties, entails a computational system that joins the two components of the mind dealing with sound and meaning. As to Zwart (1998), the computational system of human language interacts with the external systems via two distinct interface levels, the Phonetic form and the Logical form. Cook and Newson (1996, cited in Bourke, 2005, p. 90) assert that "the sounds are the external face of language [, whereas] the meanings are the internal face of language". In a sense, Bourke (2005) puts forth that "the 'sounds' make up the Phonetic Form (PF) component, and 'the meanings' make up the Logical Form (LF) component” (p. 90).

In the same vein, it is necessary is ask how linguistic interpretation is represented. To pave the way in order to find a legitimate answer to this question, Zahedi (2008) claims that this can be captured by the notion of intelligibility. However, one must not confuse interpretability with intelligibility, as Chomsky (2000, p.141) warns that there is no bound on the number of legible expressions; the fact that the faculty of language is to satisfy legibility may permit generation of expressions that are unusable. Along the same line, Zahedi (2008) holds that the computational system of language may generate illegible derivations which can be rendered intelligible by the performance system and also may be genetically legible derivation not intelligible to the performance system. For example, Sara to play tennis is happy is 
illegible at the faculty of language, but it is intelligible. However, the green Iranian fur coat is sleeping, though legible, is not intelligible.

However, McGilvray (2005) claims as "meaning-sound associations are arbitrary," (p. 206) and "there is no biological relationship between them," (p. 206) and as they are only a matter of social conventions, they are "of no interest to natural scientist" (p. 206). To Zahedi (2008), this property is called "lexical creativity" (p. 41) of language, which has been ignored by Chomsky and his followers. As a result, language is a human capacity which allows one to develop various social organizations. Culture, for instance, in the form of various social organizations depends on language.

\section{F. The Role of UG in SLA}

UG is not a theory of language acquisition, as White (1998) claims, although it provides constraints on linguistic representation. UG is part of LAD which contains learning principles, the abstract rules operated on a language. Put differently, UG is part of the faculty of language that places limitations on grammars, constraining their forms (i.e., syntactic, semantic, and phonological), as well as the way they operate (i.e., the principles that the grammar is subject to). Accordingly, UG includes invariant principles and parameters. What we are interested is whether certain abstract and complex properties which are undetermined by the L2 input manifest themselves in interlanguage grammars. Thus, in addition to a theory of constrains on interlanguage representation, we need a theory of how that representation is acquired, a theory of development. What is implicit is a central question: If the properties are innate and do not have to be learned, how does UG contribute to an explanation of language acquisition? Accordingly, White (1998) remarks:

It is the claim that, at least in the case of first languages, there is a logical problem of language acquisition, a mismatch between what goes in (namely, the primary linguistic data) and what comes out (a grammar). In other words, the input underdetermines the output. Assuming a logical problem of L1 acquisition, people have asked whether the same holds true of L2. (p. 2)

Is UG available to L2 learners? In other words, does interlanguage grammar show evidence of being constrained by principles of UG? As White says, if interlanguage grammars are UG constrained, then we expect parametric properties to show up, either in the form of L1 settings or L2 settings or settings found in other languages, with an associated cluster of properties.

Drawing on the principles and parameters approach, researchers (e.g., Bley-Vroman, 1983; Cook, 1997) made an attempt to find out to what extent UG constrains SLA? Four logical possibilities have been articulated regarding the role of UG in SLA: (1) no access hypothesis, (2) partial access hypothesis (3) full access hypothesis, and (4) dual access. The first hypothesis holds that UG is totally inaccessible to the adult L2 learner; learning takes place in terms of nonlinguistic learning strategies. Partial access hypothesis, nevertheless, maintains that UG is partially available to the learner; only those parametric values characterizing the L1 grammar are available, and the rest must be learned in terms of non-linguistic learning strategies. On the other hand, according to full-access hypothesis, UG is fully available; differences in patterns of acquisition between L1 and L2 learners and the lack of completeness can be accounted for in other ways. Dual access hypothesis also contends that L2 learners have access to UG but the access to UG is partly blocked by the use of general learning strategies. Bley-Vroman (1983), however, argues that L2 learning is fundamentally different in part from L1 acquisition on the basis of differences in their outcomes. According to BleyVroman, SLA theories must explain both the representational problem and the developmental problem. In other words, as to Bley-Vroman, SLA theories have to deal with not only what L2 learners come to know, but also how they attain this knowledge. Although there is not a unanimous agreement among scholars on the legitimacy of at least one of these possibilities, accepting that UG contributes to the acquisition of L2 leads us to this claim that L2 learners are susceptible to attain unconscious knowledge that goes beyond the L2 input! Put differently, it is claimed that there might be other sources besides input that contribute to learning. If it is plausible for researchers, it is time to focus on the nature of mental representation that $\mathrm{L} 2$ learners achieve.

\section{CONCLUSION}

Minimalist program centers upon two types of questions. The first deals with how the knowledge of language is represented in the human mind. The second question is how that knowledge develops in the individual. As Lasnik (2002) enunciates, Chomsky's (1995) answer to the first question is that competence-the knowledge of language - is "a computational system whereby derivations produce structural representations" (p. 432). Chomsky's answer to the second question concerning the explanatory adequacy is that "much of the computational system is innate" (432). Further, "only the properties of particular lexical items have to be learned" (p. 432). These derivations and representations constituting linguistic competence, according to MP, conform to an economy criterion demanding that they be minimal. In the same line, MP attempts to pursue two goals. Firstly, grammar should make use of the minimal theoretical apparatus necessary to meet the criterion of descriptive adequacy, and secondly, to minimize the acquisition burden found by children in order to meet the explanatory adequacy. But such issues all take place in L1, and one should dare to say that Chomsky's language faculty does not exist in L2 learners' minds. In other words, the notion of innateness explicitly declares that L2 learners are not equipped with an innate acquisition device to acquire L2. What the present authors do not deny is that there are certainly some similarities between the acquisition of L1 and L2. In 
both, some features of MP can be traced. Learning is UG constrained and entails the acquisition of functional categories which are initially minimally specified and acquired in more depth based on the input. As Hawkins (2001, cited in Balcon, 2001, p. 312) proposes, in L2 English inflection is at first minimally specified, with aspect, tense, and agreement features added gradually. Despite these similarities, the process of acquisition seems different.

In the same vein, Herschensohn (2000, cited in Balcon, 2001, p. 312) views syntax as invariable and language development as the acquisition of morphology and the lexicon, yet there is little indication of HOW this acquisition occurs. In L1, the concept of innateness of the faculty of language is pivotal. But what about the L2? Certainly what Chomsky and his followers do insist is to investigate the process of L1 acquisition rather than that of L2 acquisition. One can, therefore, conclude that Chomsky is silent about L2. Furthermore, if we are forced to provide a connecting link between SLA and MP, we can provide tentative answers for some questions that lack both empirical and theoretical bases. However, no one ignores that the second language user takes advantage of the minimal available resources to use language that does not give us strong theoretical reasons that lend support to the penetration of minimalism into SLA.

\section{REFERENCES}

[1] Baker, M. (2001). The atoms of language. New York: Basic Books.

[2] Balcon, P. A. (2001). Minimalism and beyond: Second language acquisiton for the twenty-first century. Second Language Research, 17(3), 306-322.doi: 10.1177/026765830101700304.

[3] Bley-Vroman, R. (1983). The comparative fallacy in interlanguage studies: The case of systematicity. Language Learning 33, 1-17. doi:10.1111/j.1467-1770.1983.tb00983.x.

[4] Boeckx, C. (2006). Linguistic minimalism: Origins, concepts, methods and aims. Oxford: Oxford University Press.

[5] Bourke, J. M. (2005). The grammar we teach. Reflections on English Language Teaching 4, 85-97.

[6] Chomsky, N. (1957). Syntactic structures. Paris: Mouton.

[7] Chomsky, N. (1995) The minimalist program. Cambridge: MIT Press.

[8] Chomsky, N. (2000). The minimalist inquiries. In R. Martin, D. Michaels, \& J. Uriagereka (Eds.), Essays on minimalist syntax in honor of Howard Lasnik (pp. 89-155). Cambridge: MIT Press.

[9] Cook, V. (1997). Monolingual bias in second language acquisition research. Revista Canaria de Estudios Ingleses 34, 35-49.

[10] David, A. (2003). Core syntax. A minimalist approach. Oxford: Oxford University Press

[11] Halliday, M. A. K. (1973). Language in a social perspective: Explorations in the functions of language. London: Edward Arnold.

[12] Lasnik, H. (2002). The minimalist program in syntax. Trends in Cognitive Science, 6 (10), 432-437. doi:10.1016/S13646613(02)01977-0.

[13] Longa, V. M., \& Lorenzo, G. (2008). What about a really minimalist theory of language acquisition? Linguistics, 46 (3), 541 570.

[14] Maftoon, P., \& Shakouri, N. (2012). Grammar is not autonomous. British Journal of science, 7 (2), 17-25.

[15] McGilvray, J. (2005). Meaning and creativity. In J. McGilvray (Ed.), The Cambridge companion to Chomsky (pp. 204-222). Cambridge: Cambridge Universsity Press.

[16] Radford, A. (1997). Syntax: A minimalist introduction. Cambridge: Cambridge University Press.

[17] Schwartz, B. (1997). On the basis of the basic variety. Second Language Research 13, $386-402$. doi:10.1191/026765897670070857.

[18] Thornton, R., \& Wexler, K. (1999). Principle B, ellipsis, and interpretation in child grammar. Cambridge, MA: MIT Press.

[19] White, L. (1998). Universal Grammar in second language acquisition: The nature of interlanguage representation. In A. Juffs, T. Talplas, G. Mizera, \& B. Burtt (Eds.), Proceedings of GASLA IV (pp. 3-14). Pittsburg: University of Pittsburgh.

[20] Zahedi, K. (2008). Determinist inquiries: Debates on the foundation of language. International Journal of Criminology and Sociological Theory, 1 (1), 26-50.

[21] Zwart, J. W. (1998). The minimalist program. J. Linguistics, 34, 213-226.doi:10.1017/S0022226797006889.

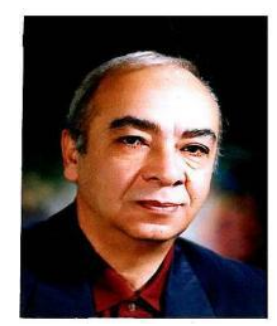

Parviz Maftoon is Associate Professor at Islamic Azad University, Science and Research Branch, Tehran, Iran. He received his Ph.D. degree from New York University in TESOL in 1978. His research interests concern SLA, SL/FL teaching methodology, and language syllabus design. He has published nationally and internationally and written and edited a number of books. He is currently on the editorial board of some language journals in Iran. 


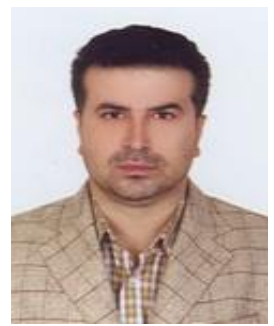

Nima Shakouri is currently a Ph.D. candidate of TEFL at Islamic Azad University, Science and Research Branch, Tehran, Iran. He has taught English courses for over a decade at different universities. Moreover, he has published nationally and internationally. 